\title{
Livros científicos, saberes ilustrados e condutas "sediciosas" de leitura na livraria do cônego Luís Vieira da Silva (Minas Gerais, Brasil, 1789)
}

\section{Scientific Books, Illustrated Knowledge and Reading Seditious Conduct in the Luís Vieira da Silva Canon's Library (Minas Gerais, Brazil, 1789)}

\author{
André Figueiredo Rodrigues \\ (D) http://orcid.org/0000-0001-9286-089X \\ Universidade Estadual Paulista Júlio de Mesquita Filho (UNESP) \\ Campus de Assis, São Paulo, Brasil \\ andre.f.rodrigues@unesp.br
}

Resumo: $\mathrm{O}$ artigo analisa a presença de livros com temas relacionados à ciência e aos saberes ilustrados na livraria do cônego Luís Vieira da Silva, um dos implicados na Inconfidência Mineira de 1789. No contexto se discutem a relação de seus livros, os saberes locais e algumas práticas "sediciosas" de leitura, proporcionadas pelas ideias revolucionárias que circulavam em Minas Gerais na segunda metade do século xviII, vindas da Europa e da América do Norte.

Palavras-chave: livros científicos; práticas de leitura; sequestro-livros; Inconfidência Mineira.

cómo citaR: Rodrigues, A. F. (2020). Livros científicos, saberes ilustrados e condutas "sediciosas" de leitura na livraria do cônego Luís Vieira da Silva (Minas Gerais, Brasil, 1789). Secuencia (107), e1700. Dor: https://doi.org/10.18234/secuencia.v0i107.1700

\section{c) 98}

Esta obra está protegida bajo una Licencia Creative Commons Atribución-NoComercial 4.0 Internacional. 
Abstract: The article analyzes the presence of books with themes related to Science and the illustrated knowledge in the library of the canon Luís Vieira da Silva, one of those implicated in the Inconfidência Mineira of 1789. In the context discusses the relation of his books, local bodies of knowledge and some "seditious" reading practices, provided by the revolutionary ideas that circulated in Minas Gerais in the second half of the eighteenth century, coming from Europe and North America.

Keyword: scientific books; reading practices; seizure-books; Inconfidência Mineira.

Resumen: El artículo analiza la presencia de libros con temas relacionados con la ciencia y el conocimiento ilustrados en la biblioteca del canónigo Luís Vieira da Silva, uno de los involucrados en la Inconfidência Mineira de 1789. En el contexto, se discute la relación de sus libros, el conocimiento local y algunas prácticas de lectura "sediciosas", proporcionadas por las ideas revolucionarias que circularon en Minas Gerais en la segunda mitad del siglo XVIII, procedentes de Europa y América del Norte.

Palabras clave: libros científicos; prácticas de lectura; incautación-libros; Inconfidência Mineira.

Recibido: 10 de enero de 2019 Aceptado: 2 de septiembre de 2019

Publicado: 11 de mayo de 2020

\title{
INTRODUÇÃO
}

\begin{abstract}
A s relações de obras de uma livraria são uma das fontes mais significativas A para se estudar a posse de livros e as suas possíveis evidências de leitura. Estes inventários, como ferramenta de análise histórica, permitem desvendar a existência de uma cultura livresca em uma determinada sociedade e época, como revelar práticas e maneiras de apropriação das ideias ali contidas ou pelo menos uma intenção ou indício de leitura. Também nos possibilita estu-
\end{abstract}


dar as redes de comunicação e de comércio que vão do autor ao público leitor, passando pelo editor, ou livreiro, ou impressor, ou distribuidor, ou vendedor, em um amplo circuito de interrelações econômicas, sociais, políticas e culturais (Chartier, 1990, p. 121; Darnton, 1990; Villalta, 2015, p. 17).

No Brasil, nos últimos vinte anos, a reconstrução da história do livro e da leitura no período colonial (de 1500 a 1808) foram realizados por estudiosos de diversas áreas do conhecimento que em suas pesquisas debruçaram-se sobre os usos de variadas fontes interdisciplinares e diversos procedimentos metodológicos, ${ }^{1}$ como ao se analisar os sequestros de bens materiais de uma pessoa presa e os inventários pós-morte, que ajudaram a evidenciar obras encontradas em bibliotecas privadas; ou os catálogos de livrarias; as operações de compra e venda de livros; os processos e denúncias feitas aos comissários do Santo Ofício, que se aprimoraram na localização de obras proibidas nas bibliotecas coloniais; e as listagens de obras circuladas quando uma pessoa viajava com livros. ${ }^{2}$

Apesar dos avanços vislumbrados, aonde bibliotecas de indivíduos particulares, de grupos ou de instituições vêm sendo minuciosamente analisados, muito ainda está por ser estudado. Assim, o que pretendemos neste artigo é abordar a presença de livros com temas relacionados à ciência e aos saberes ilustrados presentes na livraria apreendida ao cônego Luís Vieira da Silva, em 1789, na cidade de Mariana, no interior de Minas Gerais, Brasil. Antes, porém, apresentamos um breve panorama da historiografia do livro

${ }^{1}$ Para isto foram fundamentais os suportes teóricos e analíticos presentes nos estudos de Daniel Mornet (Les origines intellectualles de la Révolucion Française, 1715-1787); de Robert Darnton (Boêmia literária e revolução; Edição e sedição; Os best-sellers proibidos da França pré-revolucionária; O beijo de Lamourette, entre outros); e de Roger Chartier (Leituras e leitores na França do Antigo Regime; As origens culturais da Revolução Francesa; A ordem dos livros, entre outros). Para a história do livro no contexto colonial brasileiro são pioneiros os estudos de José de Alcântara Machado, Vida e morte do bandeirante (1929), ao analisar o cotidiano e a intimidade dos moradores de São Paulo, referenciados em inventários de 1578 a 1700, mostrou a existência de poucas bibliotecas particulares; de Carlos Rizzini com O livro, o jornal e a tipografia no Brasil (1946), que revelou o mundo da cultura impressa, desde a produção do livro até as academias literárias; e Rubens Borba de Moraes com Livros e bibliotecas no Brasil colonial (1979), que, ao investigar bibliotecas institucionais, como as das entidades eclesiásticas -como a dos jesuítas- ou de acesso público como a Biblioteca Real, no Rio de Janeiro, ou a Biblioteca Pública da Bahia, legou importantes informações sobre os títulos ali existentes, a censura, os agentes e estabelecimentos dedicados ao comércio de livros e as tipografias coloniais (Villalta, 2007a, vol. 2, pp. 249-252).

${ }^{2}$ Para o universo colonial brasileiro, destacamos: Abreu (2003); Algranti (2004); Araújo (1999); Furtado (2014); Jobim (1987); Wegner (2004). 
nas Minas Gerais colonial e a biblioteca deste religioso como tema de estudos e pesquisas. Na sequência, adentramos em sua livraria, reconstruindo seus títulos e autores, assim como a análise temática das obras científicas que lá se encontravam, para, por último, aproximar seus conteúdos às transformações que se viviam nas Minas Gerais do final do século XVIII, em relação às ideias ilustradas que circulavam no lado europeu do Atlântico.

\section{A LIVRARIA DO CÔNEGO LUÍS VIEIRA E A HISTORIOGRAFIA DO LIVRO NAS MINAS GERAIS COLONIAL}

A historiografia do livro em Minas Gerais é tributária dos estudos que, de início, procuraram avaliar os livros como objetos que comprovem a existência de uma cultura livresca no século XVIII. Na época, a região, por conhecer certa sofisticação, com o produzir da primeira consciência artística do Brasil -o barroco-, em criatividade e harmonia com a escultura, a pintura, a música e a arquitetura, incrementada com notas próprias; e ao "desenvolvimento" oportunizado pela exploração do ouro, proporcionou -relacionando-se às letras- que membros das camadas proprietárias tivessem acesso a textos e à efervescência produzida pela Ilustração e pelas transformações políticas que variam a Europa e a América do Norte na segunda metade daquele século. Tais transformações estimularam debates e contestações, assim como suscitaram receios do desmantelamento da ordem, fosse ela social, religiosa, cultural ou política. E os livros surgem como um dos elementos para isto (Rodrigues, 2002, pp. 20-21; Villalta, 2007a, vol. 2, p. 251).

Em 1901, ao conduzir a transcrição e a publicação de uma série de documentos da Inconfidência Mineira (1789), movimento que pretendia libertar a capitania de Minas Gerais da exploração econômica sofrida de Portugal, Francisco Inácio Marcondes Homem de Melo divulgou o escrutínio dos livros que compunham a livraria do cônego Luís Vieira. (Seqüestro, 1901, pp. 159-160) Este ato inaugurou -por assim dizer- a historiografia do livro nas Minas Gerais setecentistas (Rodrigues, 2010, pp. 38-39).

Na sequência, em 1945, Eduardo Frieiro (1981, pp. 18-22) examinou pioneiramente esse catálogo no primeiro ensaio de seu livro $O$ diabo na livraria do cônego, ao tecer breves notas de alguns dos títulos ali encontrados e a sua 
relação com as ideias europeias setecentistas, sem, contudo, examinar pormenorizadamente as obras relativas às ciências.

Dedicando-se ao estudo das bibliotecas existentes nas Minas Gerais setecentista, Sílvio Gabriel Diniz, em 1959, publicou estudo sobre as suas composições e quem eram os seus proprietários. Neste mesmo ano, também trouxe a público artigo sobre o comércio e a circulação de livros na cidade de Vila Rica (Diniz, 1959a, pp. 333-344; 1959b, pp. 180-195).

Em 1964, E. Bradford Burns estudou a relação dos livros do acervo da Biblioteca Municipal de São João del-Rei, organizada em 1824 a partir das obras que pertenceram aos inconfidentes José de Resende Costa, pai e filho, e ao político João Baptista Caetano de Almeida, da primeira metade do século XIX (Burns, 1964, pp. 430-438).

Após mais de duas décadas e procurando identificar práticas de leitura e a presença de livros de conteúdo ilustrado, revolucionário e herético em bibliotecas particulares, Paulo Gomes Leite (1995, pp. 153-166; 2001, pp. 217-226) publicou alguns artigos em que analisa o acervo bibliográfico pertencente ao advogado José Pereira Ribeiro, morador de Vila Rica e amigo do cônego Luís Vieira, com quem compartilhava livros e ideias sediciosas.

Guiando-se por semelhante percurso analítico, Luiz Carlos Villalta (1997, pp. 331-385; 2007b, pp. 289-311; 2007c, pp. 579-607; 2015; Villalta y Becho, 2007, pp. 555-579), do mestrado ao doutorado, passando por vários capítulos e artigos de periódico, empreendeu análise sobre os usos dos livros no mundo luso-brasileiro, destacando suas práticas de leitura, os usos que lhes foram atribuídos pelos leitores e a composição das bibliotecas e livrarias apreendidas aos inconfidentes. E dentro de seus estudos, a figura de Luís Vieira da Silva aparece referenciada e amplamente discutida.

A partir dos anos 2000, no âmbito da pós-graduação, o avançar de pesquisas sobre o universo livresco mineiro colonial, com a ampliação do repertório de fontes e dos procedimentos quantitativos e metodológicos, possibilitou encontrar e reconstituir, com mais precisão, o escrutínio de bibliotecas particulares e institucionais. ${ }^{3}$ Por ser a relação de autores e títulos surgidos a partir de então muito extensa, e por este não ser o foco deste artigo, limita-

${ }^{3}$ De igual maneira, advertimos aos leitores que, apesar de significativos, os estudos sobre as bibliotecas localizadas em outras regiões da América ibérica, como Bahia, Pernambuco, São Paulo ou Rio de Janeiro, não estão aqui contemplados, pois extrapolaria o escopo proposto, que é analisar as obras de caráter científico encontradas na livraria do cônego Luís Vieira da Silva. Os interessados em conhecer sobre bibliotecas coloniais além do espaço mineiro podem 
mo-nos a apenas informar dois destes textos que tiveram o cônego Luís Vieira como personagem. Rafael de Freitas e Souza e Júnia Ferreira Furtado com Heloísa Murgel Starling empreenderam análises sobre as múltiplas interpretações que os textos constitucionais norte-americanos, reunidos sob o título de Recueil des loix constitutives des colonies angloises, confédérées sous la dénomination d'États-Unis de l'Amérique-Septentrionale (Coleção das leis constitutivas das colônias inglesas confederadas sob o nome de Estados Unidos da América Setentrional, 1778), exerceram sobre os inconfidentes e, dentre eles, o cônego Luís Vieira (Furtado y Starling, 2013, pp. 107-132; Souza, 2008).

\section{AS OBRAS CIENTÍFICAS NA LIVRARIA DO CÔNEGO LUÍS VIEIRA DA SILVA}

Da biografia de Luís Vieira da Silva sabe-se que nasceu em Soledade, atual Lobo Leite, em Minas Gerais. Não se conhece a data de seu nascimento, apenas que foi batizado na paróquia de Congonhas do Campo, em 21 de fevereiro de 1735. Era filho do alferes português Luís Vieira Passos, que vivia da lavoura e de seu ofício de carpinteiro, e da portuguesa Josefa Maria do Espírito Santo. Eles se casaram no Brasil em 18 de novembro de 1733 e viviam na fazenda do Guido, em Soledade (Jardim, 1989, p. 277).

Em 17 de agosto de 1750, matriculou-se no Seminário de Nossa Senhora da Boa Morte, em Mariana. Ali permaneceu por dois anos, até que, em dezembro de 1752, seguiu para o Colégio dos Jesuítas, em São Paulo, para cursar filosofia e teologia moral. Concluiu os estudos em 1757 (Trindade, 1953, vol. 1, pp. 61-67). Regressou a Mariana e assumiu, "antes de ser ordenado, o cargo de professor de Filosofia do seminário, cadeira que ocuparia por 32 anos, até ser preso em 1789". Ordenou-se padre da arquidiocese de Mariana em 23 de março de 1759. Em 24 de março de 1783 tomou posse como cônego (Jardim, 1989, pp. 277-279).

Foi nos trinta e dois anos como professor do seminário de Mariana que Luís Vieira constituiu a livraria que lhe foi sequestrada e que aparece minuciosamente descrita no processo-crime denominado Autos de Devassa, aber-

consultar, além das obras referenciadas nas notas 1e 2, os estudos de Lessa (1946, pp. 339-345); Abreu (2003); e o organizado por Mollier (2006). 
to para julgar e punir os envolvidos no movimento rebelde de 1789, a Inconfidência Mineira.

Em 22 de junho de 1789, no mesmo dia de sua prisão, procedeu-se ao sequestro de seus bens materiais. Foram apreendidos móveis, roupas, um escravo de nome Cipriano, dois cavalos, utensílios domésticos, uma luneta e treze mapas emoldurados em jacarandá preto torneado. Mas, de seu patrimônio, o que impressiona é a riqueza com que o escrivão José Luís França Lira descreveu os livros que estavam armazenados em "duas estantes de pau". Havia, também, "uma mesa de madeira branca lisa com gaveta" para leitura e escrita. Provavelmente era sobre esta escrivaninha que ficava a tesoura -também apreendida- que utilizava para cortar papel e abrir as páginas laterais e superiores de seus livros, já que os seus formatos correspondiam ao número de vezes que se dobrava uma folha para formar um caderno e que este deveria ser cortado para poder ser manuseado e lido. ${ }^{4}$

A lista de seus livros, com a indicação de seu formato e aparência, indica 267 títulos distribuídos em 569 volumes. ${ }^{5}$ Mas, como informado por Eduardo Frieiro, pioneiro no estudo desta biblioteca, "o melhor [...] não estava na quantidade, mas na qualidade das obras reunidas", mostrando uma boa diversificação temática, que cobria de assuntos religiosos aos políticos, além de apresentar uma excelente seleção de autores e marcante atualidade (Frieiro, 1981, p. 24; Rodrigues, 2017, p. 13).

Apesar de poucos títulos, a quantidade de livros apreendidos ao cônego Luís Vieira impressiona no contexto das bibliotecas existentes na cidade de Mariana. Luiz Villalta (2015, pp. 358, 376; 2007b, vol. 2, pp. 292, 302), um

${ }^{4}$ Os sequestros, por se constituírem processos a parte da devassa da Inconfidência, nunca foram publicados integralmente. Apenas parte de seus traslados encontram-se impressos na versão mais recente dos Autos de Devassa em seu sexto volume, de 1982 ("Traslado do sequestro feito ao cônego Luís Vieira da Silva", pp. 83-93). As informações tipográficas e os títulos dos livros aqui apresentados foram extraídos de maneira original da versão manuscrita dos autos de sequestro custodiados no Instituto Histórico e Geográfico Brasileiro, no Rio de Janeiro, sob o título de "Autos de sequestro em bens do cônego Luiz Vieira da Silva. 1803. [códice DL 70.11]". Já no tocante aos depoimentos, utilizamos a versão impressa, que, para este quesito, reproduz de maneira completa o processo judicial. Ver: Autos de Devassa da Inconfidência Mineira (1976-1983). Nas referências, a partir de agora, a indicação a essa fonte impressa aparecerá grafada pela sua abreviatura ADIM, seguida do ano, número de seu volume e página.

${ }^{5} \mathrm{Na}$ historiografia, os números de seus livros são discordantes. Frieiro atribuiu àquela livraria 270 títulos distribuídos em cerca de 800 volumes. Paulo Gomes Leite indicou 276 obras em 563 exemplares. Villalta apontou 279 obras e 612 volumes (Frieiro, 1981, p. 20; Leite, 1995, p. 156; Villalta, 2007b, vol. 2, p. 302). 
dos mais importantes estudiosos da posse e dos usos dos livros no mundo luso-brasileiro sob o Reformismo ilustrado português, ao examinar 911 inventários de leigos e clérigos existentes no Cartório do $2^{\circ}$ Ofício da cidade de Mariana, de 1714 a 1822, descobriu a existência de 76 bibliotecas ali instaladas e um montante de 1253 obras, em um total de 2031 volumes.

Na composição das livrarias, de acordo com Luiz Villalta (2015; 2007b), os religiosos formavam a categoria, em termos numéricos, "mais expressiva dentre os proprietários de livros". "De um total de 37 clérigos inventariados, 22 possuíam livros, o que corresponde a 59.45\% do número de padres, $28.94 \%$ do conjunto de inventários com livros." A maior biblioteca pertencia ao doutor José Pereira Ribeiro, advogado e também citado nos Autos de Devassa da Inconfidência Mineira, com 211 títulos em 476 volumes. Em segundo lugar estava a livraria do padre Manuel da Cunha Osório, "professor do colégio do Sumidouro, termo de Mariana”, com 125 títulos. Na terceira colocação encontrava-se a biblioteca do coronel João Batista de Figueiredo Leitão com 73 títulos em 125 volumes. Na quarta posição, empatados com 64 títulos cada um, estavam as livrarias do padre Francisco Soares Bernardes, com seus 130 tomos, e a do advogado Jacinto de Figueiredo Vieira de Andrade, com 162 volumes (pp. 359, 376; vol. 2, p. 302).

Esses números são distintos dos apurados em outras bibliotecas existentes naquele local e arrolados em outra tipologia documental: os Autos de Devassa da Inconfidência Mineira, que nos permitem vislumbrar que dentre os presos por participação no movimento rebelde de 1789, o cônego Luís Vieira era o que detinha a maior livraria (267 títulos em 569 volumes). Dos demais clérigos envolvidos na Inconfidência Mineira, em número de cinco, apenas dois deles tiveram livros apreendidos: o padre Manuel Rodrigues da Costa com 75 títulos em 210 volumes e o padre Carlos Correia de Toledo com 60 obras em 104 volumes. Por exemplo, a livraria do bispo de Mariana à época da Inconfidência, dom frei Domingos da Encarnação Pontevel, falecido em 1793, continha 412 títulos e 1056 volumes. Já o português dom frei Manuel da Cruz, primeiro bispo de Mariana e responsável pela cerimônia de ordenação de Luís Vieira às ordens sacras, tinha 36 títulos distribuídos em 79 volumes, quando de sua morte ocorrida em 1764 (Villalta, 2007b, vol. 2, p. 306).

Esses dados ilustram o quanto era representativa a biblioteca do cônego Luís Vieira: a segunda maior da cidade de Mariana, encontrando-se ali uma boa diversificação temática, com assuntos como religião, filosofia, jurisprudência, literatura, ciências e conhecimentos úteis, do antigo ao moderno, 
"sensível às inovações que ocorriam nas ideias científicas, políticas e filosóficas" da Europa da segunda metade do século XVIII. Os melhores clássicos da cultura ocidental estavam presentes, como Anacreonte, Catulo, Cícero, Demóstenes, Horácio, Júlio César, Ovídio, Petrônio, Quintiliano, Sêneca, Suetônio e Virgílio; assim como escritores modernos como Luís de Camões, Corneille, Francisco Sá de Miranda, Pietro Metastásio, François Fénelon, Racine e John Milton. Livros de autores da Ilustração como o espanhol divulgador de ideias francesas padre Benito Jerónimo Feijoo, Condillac, David Hume, Denis Diderot, Antonio Genovesi, Marmontel, Mably, Bielfeld, Bossuet, Montesquieu, Luís Antônio Verney, Voltaire e William Robertson também estavam ali. Mas, no todo, não havia livros específicos sobre o Brasil (Frieiro, 1981, pp. 24, 29-30; Rodrigues, 2017, p. 13; Villalta, 1997, p. 364).

No escrutínio prevalecia títulos religiosos -liturgia, história sagrada, cânones, devoção, teologia, dicionários eclesiásticos e história eclesiástica-, muito em virtude de sua atuação profissional. Lá estavam os doutores da Igreja: Santo Agostinho, Santo Ambrósio, São Jerônimo e São Gregório; e obras de pensadores afinados com a ortodoxia clerical como São Bernardo, Carlos Joaquim Colbert e Petrus Collet (Frieiro, 1981, p. 26; Villalta, 1997, p. 364).

Para um professor de filosofia não podia faltar obras de lógica, metafísica e filosofia, como a Summa theologica (Suma teológica) de São Tomás de Aquino, os Éléments de métaphysique sacré et profane (Elementos de metafísica sacra e profana) do padre jesuíta François Para du Phanjas, Disputationes metaphysicae (Disputações metafísicas) do padre jesuíta Silvestre Aranha, a Metaphysica (Metafísica) e a Lógica de Antonio Genovesi, o Compendium philosophicum theologicum (Compêndio teológico e filosófico) de Manuel Inácio Coutinho e a Encyclopédie (Enciclopédia) de Denis Diderot e Jean d'Alembert.

Já no tocante às obras científicas e de conhecimentos úteis, estas se faziam presentes em boa quantidade: 45 títulos em 109 volumes. ${ }^{6}$ De medicina se destacam os quatro volumes in-octavo da Exposition anatomique de la structure du corps humain (Exposição anatômica da estrutura do corpo humano) do ana-

${ }^{6}$ Os livros do cônego Luís Vieira podem ser classificados em: livros religiosos (96 títulos em 225 volumes), jurisprudência (17 títulos em 39 volumes), história (24 títulos em 82 volumes), literatura ( 85 títulos em 114 volumes) e ciências ( 45 títulos em 109 volumes). Vale a ressalva que, em virtude dos sequestros e dos arranjos políticos ali evidenciados, muitos dos livros dos inconfidentes, assim como parte de seus patrimônios, se extraviaram, inclusive manuscritos de obras cuja existência era conhecida, mas que não foram encontrados nos escrutínios (Rodrigues, 2010, pp. 64-76). 
tomista Jacques-Bénigne Winslow (1669-1760), da Academia Real de Ciências da França e professor da Faculdade de Medicina da Universidade de Paris, publicado em 1732 e considerado o mais importante trabalho de anatomia descritiva do século XVIII.

Do médico psiquiatra e químico escocês William Cullen (1710-1790) havia dois volumes in-octavo de seu Éléments de médicine pratique (Elementos de medicina prática), que introduz, pioneiramente, na ciência moderna, um sistema classificatório de doenças (a nosologia). É considerado figura central da Ilustração escocesa. Era amigo e médico do filósofo David Hume e mantinha muito boas relações pessoais com Adam Smith. De 1773 a 1790, exerceu o cargo de primeiro médico do rei da Escócia e como professor da Escola Médica de Edimburgo, ajudou a transformá-la no principal centro médico do mundo de língua inglesa (Doig, 1993, pp. XII-XIII; Former, 2006, p. 222).

Em suas estantes também encontramos o Traité des maladies vénériennes (Tratado de doenças venéreas), em um volume in-octavo, do mestre em cirurgia francês Pierre Fabre (1716-1793); as Institutions de médicine pratique (Instituições de medicina prática) de Philipe Pinel (1745-1826), pioneiro no tratamento de transtornos mentais e precursor da psiquiatria moderna, em dois volumes in-octavo; e as Oeuvres (Obras) do médico neurologista suíço Auguste David Tissot (1728-1797), em sete volumes in-octavo, que ajudou a popularizar a prática da vacina. Provavelmente dentro do conjunto bibliográfico Oeuvres estava encartado o seu mais famoso texto Avis au peuple sur sa santé (Aviso ao povo acerca de sua saúde), de 1761, considerado o "maior best-seller médico do século xviII". Suas proposições foram reconhecidas e divulgadas pelos filósofos Immanuel Kant e Voltaire (Singy, 2010, pp. 769-800).

A presença desses livros no escrutínio talvez se explique pelo interesse que havia na época pela aplicação prática da medicina, para que se cubra uma das necessidades prementes da sociedade colonial naquela época: a saúde da população. É factível a hipótese que o cônego era um entendido na arte de curar, a fim de impedir que muitos doentes fossem vítimas da ignorância de curandeiros, barbeiros ou sangradores, que no Brasil colonial abundavam nas vilas, cidades e áreas do interior, exercendo atividades médicas práticas que necessitavam apenas do uso das mãos.

O cônego como um prático da medicina e preocupado em dar a conhecer aos moradores de Mariana formas de manter a higiene e a saúde, onde, muitas vezes, médicos não se faziam presentes, utilizava-se dos escritos de ciências baseados na experimentação e na prática clínica existentes em sua 
livraria para reproduzir e incorporar princípios médicos de autores que defendiam a medicina moderna, adaptando-os as manifestações próprias das enfermidades existentes nos trópicos e as possibilidades de tratamento disponíveis em Minas Gerais.

Ao interpretar os conteúdos daqueles livros, Luís Vieira, muito provavelmente, ajustava os princípios que ali estavam escritos aos problemas encontráveis nos lugares por onde andava em ações pastorais, procurando diminuir as moléstias decorrentes das más condições de saúde e higiene da população (Abreu, 2010, pp. 225-250). ${ }^{7}$ Supostamente praticava -como era hábito entre religiosos, de acordo com Ana Carolina de Carvalho Viotti- uma espécie de medicina casuística, atuando caso a caso, com foco no doente e não na doença, "prescrevendo receitas com ingredientes disponíveis nas hortas das casas ou no campo ao redor, constituído por plantas locais, capazes de substituir, com vantagem, as plantas europeias, de difícil acesso e caras" (Arantes, 2018). O acesso a orientações preceituadas por médicos ajudava a evitar que vigaristas enganassem os doentes.

Ali também se encontrava, como parte do paradigma médico, o livro Astronomicon (Astronomia), do poeta e astrólogo romano Marcus Manilius (século I d. C.), em um volume in-quarto, na qual apresentou, de maneira pioneira, as doze casas do sistema astrológico e os signos do zodíaco, ligados aos assuntos humanos. Na obra apresenta opiniões sobre a natureza dos cometas e sua associação às calamidades que podem provocar para a agricultura e a navegação. A edição apreendida pela devassa é a de 1739, organizada pelo filólogo Richard Bentley. Dentre os seus pertences também havia uma luneta.

A física, a agronomia e a botânica também estavam contempladas e em sintonia com a medicina e a farmacopeia da época. Ali estavam os dois volumes in-quarto da obra Physicae elementa mathematica (Elementos matemáticos da filosofia natural), do físico, matemático e filósofo holandês Willem Jacob's Gravesande (1688-1742), divulgador dos princípios da "filosofia natural" de Isaac Newton, de 1720, e considerado o descobridor da energia cinética, o construtor do primeiro heliostato e inventor do anel de Gravesande, instru-

${ }^{7} \mathrm{Na}$ América portuguesa era comum que proprietários alfabetizados de fazendas, de engenhos e de escravos tivessem entre seus bens materiais livros de medicina voltados para o uso doméstico e prático. Pedro Nava, em seu estudo sobre a medicina "popular" no Brasil, informa que muitos senhores exerciam práticas médicas adquiridas "na capação de porcos e bezerros", fazendo incursões pela cirurgia no coser de "muita barriga aberta e pondo no lugar muita tripa exposta a pontaço de chifre e a fio de "lambedeira" (Nava, 2003, p. 125). 
mento metálico de estudo da dilatação e da contração volumétrica de corpos por variação de temperatura. Outro sábio holandês, discípulo e amigo de Gravesande, que também teve duas de suas obras na estante do cônego foi Pieter van Musschenbroek (1692-1761), com Essai de physica (Ensaio de física), um volume in-octavo, e Physica (Física), em dois volumes in-octavo, que ajudaram igualmente a propagar a filosofia experimental e as ideias de Newton (Ducheyne, 2016, p. 123). Ao lado destes havia a Physica (Física) de Zanesi, em dois volumes in-octavo, e um Nouveau dictionnaire des scienses (Novo dicionário de ciências), em dois tomos in-octavo, sem indicação de autoria.

As ciências práticas e seus conhecimentos úteis ao dia a dia também se fizeram representar no livro Manuel d'agriculture (Manual de agricultura), um volume in-octavo, sem o nome do autor, mas que provavelmente seja a edição do agrônomo francês Simon Philibert de La Salle de l'Etang (1700-1765), muito lida na época.

O gosto pela ciência também se fazia presente nos livros de viagens, história natural, geometria, química e geografia. Lá estavam, como marcas da objetividade e do empirismo da Europa moderna, os quatro volumes in-octavo das Voyages au tours $d u$ monde (Viagens pelo mundo), do naturalista e botânico inglês Joseph Banks (1743-1820), de sua viagem pelo mundo, de 1768 a 1771, na expedição científica comandada pelo explorador e cartógrafo inglês James Cook aos mares do sul, para formar sua coleção de plantas e insetos. Acompanhado por uma pequena comitiva, que contou, entre outros, com a presença do naturalista sueco Daniel Carl Solander, discípulo de Carlos Lineu (o pai da biologia moderna, por ser o criador das classificações dos seres vivos), Banks empenhou-se em sistematizar espécies de plantas e defender a natureza internacional da ciência, sendo considerado uma das pessoas mais influentes das ciências no século XVIII (Lysagth, 2003).

Da química, os quatro volumes in-octavo de Elements de mineralogie docimastique (Elementos de mineralogia docimástica), de 1772, do químico e mineralogista francês Balthasar-Georges Sage (1740-1824), de grande êxito editorial; e Secret concernant les arts et les métiers (Preocupação secreta sobre artes e ofícios), de 1766, em dois volumes in-octavo, de autoria desconhecida, que trata dos segredos dos metais (Todericiu, 1984, pp. 29-46; Wisniak, 2013). Aliás, estes títulos mantêm estreito relacionamento com a própria história de Minas, surgida a partir da extração do ouro no final do século xviI. Naquele contexto, possuir uma obra de docimástica -ou a arte de testar metais-era importante, 
pois ensinava como analisar o teor de minerais metálicos em ligas e minérios, possibilitando saber -como indica o segundo título-os segredos dos metais.

Os conhecimentos transmitidos por estas duas obras poderiam servir aos interesses e planos propostos pelos sediciosos de 1789 que se posicionavam favoráveis em construir manufaturas e estimular a exploração de minérios de ferro e a montagem de uma fábrica de pólvora, prevendo-se a defesa da futura região independente de Minas Gerais. Ao longo do século XVIII, Minas era a área de mineração mais importante do império português.

Os conhecimentos físico-matemáticos também se revelavam na obra Geometria, em dois volumes in-octavo, do filósofo, físico e matemático René Descartes (1596-1650), o maior expoente do racionalismo clássico que, ao propor a junção da álgebra com a geometria, gerou a geometria analítica (ou cartesiana) e o sistema de coordenadas matemáticas que hoje leva o seu nome. A ele é outorgado o título de fundador da filosofia moderna, por introduzir a dúvida como elemento essencial para a investigação filosófica e científica, e o epíteto de o pai da matemática moderna (Spinelli, 1990, pp. 5-15).

Ao lado da obra de Descartes havia os Elementos de geometria plana e sólida segundo a ordem de Euclides, em um volume in-quarto, do padre jesuíta e matemático Manuel de Campos (1681-1758), impresso em Lisboa, com contribuições originais para o "estudo do volume dos sólidos mais simples, hoje relegados à matemática escolar, e que deram origem às noções de simetria e de equidecomponibilidade dos sólidos", problemas de pesquisa em fins do século XVIII (Guimarães, Pitombeira, Schubring, 2011, p. 317).

Lá também estavam os cinco volumes in-quarto da obra Elementa matheseos universae (Elementos da matemática geral) do filósofo racionalista alemão Christian von Wolff (1679-1754), um dos fundadores da economia como disciplina acadêmica e sistematizador do racionalismo do século XVIII mediante a reelaboração da filosofia de Gottfried Wilhelm Leibniz. Foi um dos grandes nomes da Ilustração alemã (Hettche, 2016).

Da história natural foram apreendidos dois títulos de livros do naturalista francês Jacques Christophe Valmont de Bomaré (1731-1807), um volume in-octavo das Memoires instructifs de l'histoire naturelle (Memórias informativas da história natural) e os seis volumes in-quarto do Dictionaire raisonné universalle d'histoire naturelle (Dicionário universal razoado de história natural), impresso em Paris entre 1764 e 1768, que contém a história de animais, plantas, minerais e dos principais fenômenos da natureza. Nesta mesma linha -a da história geral da natureza- constam os Études de la nature (Estudos da natureza) do bo- 
tânico francês Jacques-Henri Bernardin de Saint-Pierre (1737-1814), edição de 1784 , em três volumes in-octavo.

Da geografia vinham obras de autores como o abade Louis-Antoine Nicolle de Lacroix (1704-1760), com seus dois volumes in-octavo intitulados Géographie moderne (Geografia moderna), impresso em 1748; e dois dicionários geográficos escritos em francês, sendo um deles, provavelmente, a obra de Jean-Baptiste Ladvocat (1709-1765), redigida sob o pseudônimo de François-Léopold Vosgien, Dictionnaire geographique ou description de toutes les parts $d u$ monde (Dicionário geográfico ou descrição de todas as partes do mundo), de 1747, em um volume in-octavo.

Os saberes científicos transmitidos por essas obras, provavelmente proporcionaram ao cônego Luís Vieira conhecimentos da geografia e das riquezas naturais e minerais existentes em Minas Gerais, quando irromperam práticas contestatórias em 1789. Como inconfidente e um dos organizadores das ideias políticas da conspiração, foi um dos responsáveis pelo esboço das leis fundamentais do futuro estado e da estratégia militar de defesa. Não é à toa que na sua estante havia o livro Elementos de arte militar, em dois volumes in-dieciseisavo, de José Marques Cardoso, impresso em Lisboa em 1785.

Em depoimento à devassa, Domingos Vidal Barbosa Lage, que estudou medicina em Montpellier e também implicado na Inconfidência, confessou que os planos sediciosos nasceram do trabalho de Luís Vieira, e que este fizera o projeto de segurança do território. (ADIM, 1976, vol. 1, p. 214; 1978, vol. 2, p. 146).

No contexto dos acontecimentos independentistas, a obra Elementos de arte militar adequava-se aos propósitos e práticas revolucionárias militares pensadas naquele momento. $O$ interesse pela arte militar e por mapas geográficos, como os treze exemplares apreendidos entre os seus bens, permitia ao religioso melhor entender o espaço geográfico de Minas, uma vez que a posse de mapas representava um dado estratégico fundamental para o planejamento do movimento sedicioso, já que permitia conhecer, em detalhes, a organização espacial da capitania e as suas características geográficas dominantes. ${ }^{8}$

${ }^{8}$ No processo não há a descrição dos conteúdos daqueles treze mapas. Entretanto, no contexto, sabe-se que em meados da década de 1770, o sargento-mor José Joaquim da Rocha, cartógrafo, memorialista e engenheiro, foi o responsável pela elaboração de um conjunto cartográfico sobre Minas Gerais. Na devassa, foi acusado por alguns réus de ter fornecido seus mapas para subsidiar o levante. Provavelmente, dentre os treze mapas apreendidos ao cônego 


\section{SABERES LOCAIS, ILUSTRAÇÃO E INDÍCIOS DE LEITURA: O CÔNEGO LUIÍS VIEIRA E A EXPLORAÇÃO COLONIAL NAS MINAS GERAIS DA SEGUNDA METADE DO SÉCULO XVIII}

Um dos desafios enfrentados por quem pretende analisar o escrutínio de livrarias antigas está na busca pela resposta a duas perguntas, entre outras que se podem formular: possuir um livro significa o desenvolvimento de práticas de leitura? Que usos os leitores (que podiam ser seus proprietários) atribuíam aos livros?

Ao se procurar descobrir os usos explicitamente enunciados que os leitores deram aos textos que existiam em suas bibliotecas, como realizado por Luiz Villalta (2015) ao estudar os livros e as suas utilizações sob o reformismo ilustrado, entre 1750 e 1822, não se pretende -o que seria inexequível- "identificar [as] genuínas manifestações dos leitores", mas alguns de seus indícios como intérpretes de ideias que circulavam, limitando-se apenas a "aprender os usos plausiveis dos livros" (p. 325).

Como provável leitor do melhor que se produzia na Europa, Luís Vieira acolhia em sua livraria obras da Ilustração que gozavam de ampla curiosidade intelectual e notável abertura ideológica, sobretudo as impressas na França do século xviII. Em Minas Gerais se difundiram princípios filosóficos e políticos ilustrados que versavam sobre a razão, como o principal instrumento do homem para lidar com a natureza e a sociedade, assim como para exprimir um complexo processo de transformações de comportamentos, valores e atitudes, e até de funcionamento das instituições (Neves, 2000, p. 296).

Entre os séculos XV e XVIII ganharam força ideias como a de que o poder político poderia ser uma concessão da sociedade aos governantes, e não um favor de Deus; assim como a sentença de que todas as pessoas, independentes de serem nobres ou não, eram iguais e tinham os mesmos direitos e deveres. A este conjunto heterogêneo de ideias deu-se o nome de Ilustração, em oposição a um suposto obscurantismo que a Igreja católica e as instituições -a nobreza, a monarquia e a rígida hierarquia social- representariam. De acordo com os pensadores ilustrados era por meio da razão (na dicotomia de "luzes" -representativas da noção de progresso, em grande parte graças à

estejam cópias dos mapas de Rocha (ADIM, 1976, vol. 1, p. 166; 1981, vol. 4, p. 116; 1982, vol. 5, pp. 48-49). Sobre a história e a análise desses mapas, conferir: Furtado (2009, p. 155). 
ciência-e "trevas" -que se ligavam ao atraso e a ignorância) que se atingiriam os conhecimentos necessários para alcançar as leis naturais que regem a sociedade-. A ciência, segundo pensadores e cientistas dos séculos XVI e XVII, como Descartes, Leibniz e Galileu Galilei, "demonstrava que a natureza possuía leis próprias e independentes da vontade de Deus" (Furtado, 1998, p. 32).

No século XVIII, pesquisas científicas e a divulgação e "radicalização dessas ideias” alcançaram níveis sem precedentes (Furtado, 1998, p. 32). Pensadores ilustrados criticavam o absolutismo, o mercantilismo e a organização da sociedade, baseada em tradições e privilégios. Acreditavam "que o estado absolutista, em que o monarca detinha todo o poder, deveria ser substituído por um governo representativo, na forma de uma monarquia constitucional ou de uma república democrática". Condenavam a ingerência do estado na economia, que era uma característica do mercantilismo, e defendiam uma política econômica liberal, conduzida pelo livre funcionamento do mercado (Anastasia, 2002, p. 23). Ideias, aliás, que vinham ao encontro dos anseios libertários que começaram a circular na segunda metade do setecentos na região de Minas.

Ideias ilustradas entraram em Mariana, a terra de Luís Vieira e onde estava a sua importante livraria, de quatro maneiras. A primeira pela presença de intelectuais europeus vindos para a colônia. A segunda, com o regresso dos "brasileiros" que foram estudar nas universidades europeias. A terceira diz respeito à presença de colonos que foram a Europa realizar transações comerciais ou a passeio ou tratamento de saúde, por exemplo, que, ao regressar, traziam consigo o melhor da cultura do além-mar. Uma "última" foi pela palavra escrita, pois o livro foi o melhor e o mais eficiente método de difusão da Ilustração no território colonial (Rodrigues, 2002, p. 145).

Muitos estudantes "brasileiros" que regressavam da Europa traziam, entre os seus pertences, obras cujas posses e vendas eram proibidas. Outras vezes, esses livros entravam por contrabando. Paulo Gomes Leite, ao estudar a circulação de livros ilustrados em Minas nos fins do século XVIII, mostrou que um dos estratagemas mais bem empregados para se despistar as autoridades era o livro proibido entrar no Brasil sob um título suposto. Outras vezes, empregava-se a tática, muito usada pelos contrabandistas para introduzir livros na França, como revelado por Robert Darnton, de transportar os livros em folhas soltas, intercaladas por páginas de outra obra, geralmente de teologia, jurisprudência, sermões, etc., para afastar qualquer suspeita e agilizar sua liberação. Era assim que o doutor José Pereira Ribeiro, residente em Ma- 
riana e amigo do cônego Luís Vieira, transportava seus livros, fazendo chegar - por contrabando- o arsenal ideológico que ajudou a inquietar os ânimos dos mineiros e a embalar seus "sonhos libertários" (Leite, 2001, pp. 217-226). ${ }^{9}$

A Ilustração chegou às Minas Gerais na segunda metade do século XVIII, como se disse. Até aquele momento, a região não tinha nenhuma tradição no debate filosófico e não era dotada de academias literárias ou de investigação científica para promover discussões. No entanto, houve núcleos intelectuais nos quais a "dimensão crítica da tradição racional foi acolhida, a fim de expor as arbitrariedades e algumas das injustiças intrínsecas ao estatuto colonial" (Sevcenko, 1989, p. 23).

Sob o clima de despotismo e censura, a situação do letrado na sociedade colonial confrontava-se com essas forças altamente coercitivas, que representavam a condição de controle das ideias impostas pela metrópole. A intransigência grassava principalmente em áreas em que se concentravam os ávidos interesses régios, como a região mineradora de Minas Gerais. Os intelectuais ali residentes, muitas vezes escritores e leitores de si mesmos, nas horas vagas, reuniam-se em cenáculos literários, como os que ocorriam nas casas dos também implicados na Inconfidência Mineira poetas Tomás Antônio Gonzaga e Cláudio Manuel da Costa, em Vila Rica, para resolver o problema da privação cultural. Nessas reuniões, as concepções ilustradas transmitidas pelos livros de autores como Voltaire, John Locke, Rousseau, Antonio Genuense, Montesquieu, Mably, Robertson, Marmontel, Raynal, Condillac, Linguet e Bielfeld, entre outros, circulavam e os ajudavam a interpretar-mesmo que vagamente- o mundo em que viviam.

Entre os livros do cônego Luís Vieira e referindo-se a alguns desses autores, lá estava Charles-Louis de Secondat, o barão de Montesquieu (16891755), com dois de seus títulos: L'esprits des lois (O espírito das leis), em cinco volumes in-octavo, e Grandeur et décadence des Romains (Grandeza e decadência dos romanos), em seis volumes in-octavo; marcos importantes da Ilustração francesa e responsáveis por mostrar as suas concepções a respeito da monarquia e do despotismo. Em $\mathrm{O}$ espírito das leis, explica as diferenças entre as sociedades e os sistemas de governo, pela teoria da separação de três poderes: o legislativo, o executivo e o judiciário. Sua interpretação de liberdade, em oposição ao

${ }^{9}$ Em denúncia ao Santo Ofício, o padre João Luís de Sousa Saião acusou José Pereira Ribeiro de, ao embarcar de Portugal para o Brasil, trazer as Cartas persas, de Montesquieu, sob o título de Sermons de Neuville (Leite, 2001, pp. 221-222; Darnton, 1992, pp. 33-36). 
absolutismo, representado pela autoridade de um só governante, explica-se -e foi interpretada pelos intelectuais de Minas Gerais- pelo direito que as pessoas têm de poder fazer tudo o que as leis facultam, inclusive rebelar-se contra governos opressores.

Outra obra ali presente era Institutions politiques (Instituições políticas), um volume in-quarto, do barão de Bielfeld (1717-1770), um dos mais destacados expoentes da Ilustração alemã, onde se pode ler "o mais violento ataque que já se fez à Inquisição" (Leite 1995, p. 160). Com três escritos, William Robertson (1721-1793), um dos limiares da Ilustração escocesa e também crítico da Inquisição, por considerá-la repressora ao progresso das letras e da ciência, aparece com Histoire de l'Écosse (História da Escócia), três volumes in-octavo, Histoire du règne de l'empereur Charles-Quint (História do reino do imperador Carlos V), em três volumes in-quarto, e o seu texto mais importante Histoire de l'Amerique (A história da América), em quatro volumes in-quarto. François-Marie Arouet, pseudônimo de Voltaire (1694-1778) e um dos mais incendiários autores da Ilustração francesa, também ali se fez representar por um compêndio intitulado Oeuvres (Obras), em um único volume in-octavo. Igual título também foi atribuído ao conjunto de textos do abade Condillac (1714-1780), em três volumes in-octavo.

Ao lado desses autores, entre outros que também se poderiam citar, achavam-se em dois volumes in-octavo a Encyclopédie ou Dictionnaire raisonné des sciences, des arts et des métiers (Enciclopédia ou Dicionário razoado das ciências, das artes e dos ofícios), de Denis Diderot (1713-1784) e Jean d'Alembert (17171783), "a obra suprema do Iluminismo", no feliz epíteto que lhe foi atribuída por Robert Darnton ao reconhecê-la como o grande empreendimento editorial e a síntese do movimento intelectual que varreu a Europa no setecentos (Darnton, 1996, pp. 15, 24-25). Naquela livraria também existia a seleção de seus principais artigos, condensada no L'esprit de l'Encyclopédie ( $O$ espírito da Enciclopédia), em cinco volumes in-octavo.

Mas, voltando-se às tertúlias literárias, nos Autos de Devassa há informações de que alguns dos encontros "subversivos" aconteceram nas casas dos principais envolvidos na Inconfidência. Lá estabeleciam contatos e desenvolviam discussões sobre a situação local. ${ }^{10}$ Em Vila Rica, na residência do tenente-coronel Francisco de Paula Freire de Andrada, a mais alta patente militar

10 Nesses encontros havia o empréstimo e a devolução de livros. Na casa de Francisco de Paula, o poeta Alvarenga Peixoto disse ter pegado um livro por empréstimo, em depoimento 
envolvida na revolta, ocorreram os mais importantes encontros sediciosos e onde os conjurados, além de emprestar livros e debater seus conteúdos, formulavam estratégias e esboçavam os contornos da ordem que surgiria após o início da rebelião (ADIM, 1982, vol. 5, pp. 115, 172-173, 223; Villalta y Becho, 2007, vol. 2, p. 555).

Em certa ocasião, ainda em conversas ocorridas na casa de Francisco de Paula, o anfitrião, o alferes Joaquim José da Silva Xavier (o Tiradentes), o poeta Alvarenga Peixoto e os padres Carlos Correia de Toledo e José da Silva e Oliveira Rolim debateram a Histoire philosophique et politique des établissements et du commerce des européens dans les deux Indes (História filosófica e politica dos estabelecimentos e do comércio dos europeus nas duas Índias), do pensador francês abade Guillaume-Thomas François Raynal (1713-1796), obra publicada, pela primeira vez, em 1770 e que, entre outras coisas, analisa a colonização portuguesa na América e elogia as riquezas naturais ali encontradas. Nas edições posteriores a 1780, a independência dos Estados Unidos, saudada pelo autor como um modelo a ser seguido, passou a ser interpretada pelos inconfidentes de 1789, em suas aspirações de independência, como uma fórmula para fazer a revolução pela libertação da colônia (Furtado y Monteiro, 2016, pp. 738-739; Villalta y Becho, 2007, vol. 2, pp. 555-578).

A obra do abade Raynal foi muito apreciada e alcançou grande difusão, chegando alguns inconfidentes a citá-lo em seus depoimentos no processo judicial. Em sua primeira inquirição, em 16 de novembro de 1789, Francisco de Paula aludiu na conversa que teve com os quatro outros participantes que estiveram em sua casa, que o dito abade "tinha sido um escritor de grandes vistas; porque prognosticou o levantamento da América Setentrional, e que a Capitania de Minas Gerais com o lançamento do tributo da derrama, estaria agora nas mesmas circunstâncias" (ADIM, 1982, vol. 5, p. 173).

Em Minas Gerais, a partir da segunda metade do século XVIII, a mineração - a principal fonte econômica da região- entrou em retração e a quantidade de ouro estabelecida como pagamento anual para a sua extração, fixada em 1734 em cem arrobas anuais, ou 1474 quilos, começou a não ser honrada. Em 1750, foi estipulado que se esse mínimo não fosse atingido, todos os moradores da capitania teriam de pagar a diferença, mediante cobrança à força de

à devassa de 14 de janeiro de 1790 ("ao tirar um livro, como costumava") (ADIM, 1982, vol. 5, p. 114). 
um imposto individual -a derrama. ${ }^{11}$ Em 1789, a dívida que Minas devia aos cofres portugueses era de 582 arrobas de ouro ou o equivalente a 8.6 toneladas (Rodrigues, 2010, p. 19). Além de não poder saldar o que o governo exigia, a população também não tinha como quitar suas dívidas particulares. E, em meio à ameaça de se fazer cumprir a quitação daquele débito, em 1789, membros ligados diretamente à administração da capitania e aos estratos da justiça e da igreja, resolveram rebelar-se contra o domínio português na região, prefigurando o estabelecimento de uma república em Minas. A derrama, em si, seria o estopim para o início do movimento. Assim, em meio a este contexto, é que as palavras de Raynal ecoaram transvestidas em crítica as arbitrariedades e as injustiças que imperavam na manutenção do jugo colonial.

Como se disse, a História das duas Índias, a partir de sua edição de 1780, traz uma parte consagrada à Revolução Americana, que mereceu, por parte do editor, uma edição em separado, intitulada Revolução da América, de 1781, contemplando títulos do livro xVIII, tomo $4^{\circ}$ da edição de 1780 (Furtado y Monteiro, 2016, p. 738, nota 11). ${ }^{12}$ Foram estes escritos que muito influenciaram Vieira, a ponto de Alvarenga Peixoto declarar que ele tinha uma "paixão dominante" pela história da América inglesa (ADIM, 1982, vol. 5, p. 124).

Não é à toa que as principais acusações contra o cônego Luís Vieira partem do pressuposto de ser ele "sabedor e conhecedor" da emancipação norte-americana e dos fundamentos contidos na obra de Raynal (ADIM, 1982, vol. 5, p. 173). Na carta-denúncia entregue ao governador visconde de Barbacena, o tenente-coronel Basílio de Brito Malheiro do Lago descreveu uma conversa que teve com o dito clérigo, relatando que

este não encobre a paixão que tem de ver o Brasil feito uma república; abonou o Tiradentes de um homem animoso e que, se houvesse muitos como ele, que o Brasil era uma república florescente; e que um príncipe europeu não podia ter nada com a América que é um país livre; e que El-Rei de Portugal nada gastou nesta conquista, que os nacionais já a tiraram dos holandeses, fazendo a guerra à sua custa sem El-Rei contribuir com dinheiro algum para ela; depois disto, os franceses tomaram o Rio de Janeiro, que os habitadores da cidade

${ }^{11}$ Durante a segunda metade do século XVIII, a derrama foi executada em duas ocasiões: em 1763-1764 e em 1771-1772.

${ }^{12}$ Aliás, uma das edições comprovadas que circulou em Minas Gerais foi a segunda, datada de 1780, em quatro volumes, constante na biblioteca do doutor José Pereira Ribeiro, proprietário do exemplar lido pelo cônego Luís Vieira (Leite, 1995, pp. 155-156). 
lha compraram com o seu dinheiro; e ultimamente concluiu que esta terra não pode estar muito tempo sujeita a El-Rei de Portugal, porque os nacionais dela querem também fazer corpo da república; e outras coisas semelhantes que todas se encaminham ao fim da liberdade, que se pretendiam (ADIM, 1976, vol. 1, p. 102).

A república, para o cônego, era símbolo de liberdade e as palavras que lhe foram atribuídas demonstram os impasses da realidade social e política que se vivenciava em Minas Gerais, assim como aos dois grandes elementos conscientizadores do movimento inconfidente: a questão da contraposição metrópole versus colônia e o discurso das leis e dos direitos de uma nação livre e independente. Os dizeres de Vieira combinam a repulsa que se faz sentir da condição colonial e dos desmandos da metrópole; sentimentos que já estavam arraigados e na mentalidade colonial, exacerbados nas lutas contra os estrangeiros.

$\mathrm{Na}$ citação se vislumbram as ideias que fervilhavam naquele instante e palavras como "conquista", "terra", "nacionais" e "América" propalavam o sentimento que os moradores de Minas mantinham com o seu mundo colonial. O vocábulo "conquista" é um exemplo disso, uma vez que exteriorizava o sentido de que as terras do Brasil, sendo uma conquista, não eram propriedade de seus habitantes, mas uma possessão portuguesa. Esse termo anulava qualquer ideia de autonomia, já que ela era denominada e reivindicada por Portugal como uma conquista. Não obstante, Luís Vieira, na sequência de sua fala, desfaz o processo discursivo e ideológico da palavra "conquista", pois ele recorda o fato de que a conquista que realmente houve nas terras do Brasil foi a dos "nacionais" que sozinhos defenderam e expulsaram os invasores estrangeiros. Nas entrelinhas, ele disse que a conquista era dos nacionais (Focas, 2002, p. 179).

O cônego mostrava aprazimento quando conversava e lia com alguém "a história do levante da América Inglesa". Em depoimento, o contador português Vicente Vieira da Mota disse que havia nos "filhos da América tal gosto e complacência em ler a história da liberdade das Américas Inglesas, que lhe parecia que se eles tivessem outra tal ocasião, a abraçariam" (ADIM, 1982, vol. 5, pp. 417, 410). Tal fala sugestiona que, para esses leitores de Minas Gerais, a história da América inglesa servia para ler a própria história da América portuguesa e para intervir nela, refletindo a divisão entre a "opressão 
do domínio português" e a "consciência de liberdade" (Focas, 2002, p. 181; Villalta, 2015, p. 478).

O texto de Raynal foi resposta a questões incitadas por circunstâncias particulares, e seu significado está integrado ao seu contexto de comunicação (Darnton, 2014, p. 147). Os excertos discutidos foram significativos, de acordo com a maneira como foram interpretados em um tempo e local específicos. Em $A$ revolução da América lê-se:

Se os povos são felizes sob a forma de seu governo, eles o conservarão. Se são infelizes, não serão as vossas opiniões nem as minhas -será a impossibilidade de sofrer mais e por mais tempo que irá determiná-lo a mudá-las, movimento salutar que o opressor chamará de revolta, ainda que não seja mais que o exercício legítimo de um direito inalienável e natural do homem que se oprime, e mesmo do homem que não é oprimido (Raynal, 1993, p. 75).

Ou, ainda,

A autoridade de uma nação sobre uma outra só pode ser fundada sobre a conquista, o consentimento geral, em condições propostas e aceitas. A conquista não vincula mais que o roubo. $O$ consentimento dos ancestrais não pode obrigar os descendentes. E não há condição que não seja exclusiva do sacrifício da liberdade. A liberdade não se troca por nada, porque nada tem um preço que lhe seja compatível (p. 78).

As palavras de Raynal permitiram aos conspiradores questionar a situação que viviam e a proposta de rebelar era tão-somente exercer um direito próprio, ainda mais pelo fato de que Minas Gerais estava em constante opressão, em virtude da repressiva e escorchante política econômica implantada pela coroa portuguesa no local.

Dessa maneira, os acontecimentos ocorridos com os americanos do norte serviram de exemplo para as possíveis convicções de autonomia que ali se pensavam. Se tivessem igual oportunidade, não deixariam de lançar mão dela, aproveitando para fundar uma república. A obra de Raynal trazia o modo de se fazer os levantes, isto é, "cortando a cabeça ao governador e fazendo uma fala ao povo repetida por um sujeito erudito" (ADIM, 1982, vol. 5, pp. 149-150), além de pensar a revolução como uma forma de superação das injustiças e das desigualdades entre os povos. 
Os inconfidentes viram, portanto, na bem-sucedida revolução americana um modelo do que eles queriam para Minas Gerais, ao ponto de atribuírem um sentido claramente subversivo à literatura em uma determinada ocasião: em sua segunda inquirição à devassa, Alvarenga Peixoto afirmou que na casa de Cláudio Manuel da Costa ou de Tomás Antônio Gonzaga, outros locais em que se realizavam conciliábulos,

se falou em umas bandeiras, que o Alferes Joaquim José da Silva Xavier tinha ideado para servirem na nova premeditada República, que eram três triângulos enlaçados em comemoração da Santíssima Trindade, se lembrou o Doutor Cláudio Manuel da Costa das bandeiras da República Americana Inglesa, que era um gênio da América, quebrando as cadeias com a inscrição -Libertas aquo Spiritus-, e que podia servir à mesma, e o Respondente lhe disse que seria pobreza ao que ele respondeu que podia servir a letra -Aut libertas, aut nihil-, ao que o Respondente se lembrou do versinho de Virgílio -Libertas quae sera tamen-, que ele achou, e todos os que estavam presentes, muito bonito (ADIM, 1982, vol. 5, p. 122).

O verso em latim "Liberdade ainda que tardia", de Virgílio, vencedor como lema para a bandeira do território independente que se previa, traduz não apenas um sentimento poético, mas, como lembrou Villalta (2015), "a expectativa política guardada pelos conjurados no sentido de romper os grilhões que atrelavam Minas a Portugal" (p. 479).

No contexto, o plano elaborado pelo cônego Luís Vieira necessitava de um fato capaz de abalar a população. ${ }^{13}$ Este estopim seria a decretação da derrama, o elemento motivador e legitimador do processo:

no plano estabelecia o dito cônego que se devia esperar uma ocasião em que o povo estivesse desgostoso; e que depois se deviam tomar os quintos e que, agora se tratava de lançar a derrama, contou a ele, testemunha, Francisco Antônio de Oliveira Lopes que se tinha justo fazer o rompimento, avisando-se a todos para se ajuntarem com a senha de dizerem -tal dia é o batizado- com cujo aviso juntariam todos (ADIM, 1981, vol. 4, p. 147).

13 "Vieira [...] tinha feito um papel em que mostrava a segurança deste país, e o modo por que se devia fazer a rebelião” (ADIM, 1981, vol. 4, p. 146). 
Com o lançamento da cobrança da derrama, os sediciosos mineiros esperavam que, com as atitudes e reações contrárias a esse pagamento, a população se levantasse e se unisse a eles, em torno da causa inconfidente. Com o pagamento da dívida de 582 arrobas de ouro, a ser dividido entre toda a população, não importando se fossem mineradores ou não, os mineiros -mesmo não se sabendo ao certo como a cobrança seria realizada-veriam esvaírem-se todos os seus cabedais para pagar uma dívida injusta, muitas vezes, acumulada por gerações, uma vez que muitos dos devedores já estavam mortos ou tinham se retirado das áreas auríferas por causa da retração da produção (Jardim, 1989, pp. 34, 351).

Para ludibriar o inquiridor sobre o seu real envolvimento na Inconfidência, Luís Vieira apropriou-se de outros textos de sua biblioteca, de maneira sediciosa, como livros que narram à história do movimento de Restauração portuguesa de 1640, tais como Histoire génerale de Portugal (História geral de Portugal) do historiador francês Nicolas de la Clède (1700-1736), em três volumes in-octavo, e História genealógica da Real Casa Portuguesa, de Antônio Caetano de Sousa (1674-1759). Para contradizer a importância da derrama e expor a hipótese sobre as condições que não tornariam executáveis um movimento de libertação em território mineiro em 1789, o cônego disse em depoimento à devassa da Inconfidência:

Sabe que na feliz aclamação de El-Rei D. João o quarto, sendo uma causa tão justa, e tanto da vontade dos povos, perguntou, segundo a sua lembrança, D. João da Costa, quais eram os generais, as armas, as alianças, os soldados, que tinham prontos para se levantarem contra as armas de Castela, e que isto foi bastante para se suspender a ação por oito dias, e talvez se não executasse, se nisso não tivesse o maior perigo; e como poderia pensar que tivesse feito a sublevação de Minas falta de tudo o necessário (ADIM, 1982, vol. 5, p. 248). ${ }^{14}$

O conteúdo implícito dessa narração, feita mediante uma analogia entre a Inconfidência e a Restauração portuguesa de 1640, permite-nos pensar, como faz Villalta, numa comparação entre ambas, colocando-as em um mesmo patamar. Consequentemente, se o movimento pela Restauração foi uma agitação "justa" e da "vontade dos povos", o movimento sedicioso mineiro, estando assemelhada a ela, também seria. Se para o cônego a Inconfidência

${ }^{14}$ O primeiro a desenvolver esta explicação foi Villalta (2015, pp. 459-500). 
“equipara-se à Restauração”, logo era também “uma causa justa, da vontade dos povos"; enfim, "uma sedição legítima!" (Villalta, 2015, p. 490).

Ao propor um movimento legítimo nas Minas, o cônego esteve imbuído da filosofia ilustrada. O mais importante é que considerava um levante contra o monarca algo legítimo da "vontade dos povos", a exemplo do exposto por Montesquieu em $O$ espírito das leis. Ao negar o princípio legitimador do poder régio, realizava uma crítica ao absolutismo, também presente em filósofos como Rousseau e Voltaire. Como ávido leitor das filosofias revolucionárias setecentistas, esteve a par das ideias de igualdade social, direito à liberdade e garantia do uso e desfrute da terra pelos colonos. Mas, acima de tudo, os princípios norteadores de seu filosofismo vieram do abade Raynal (Rodrigues, 2002, pp. 149-150; Villalta, 2015, p. 490).

Como admirador do processo independentista norte-americano, o cônego também se "apaixonou" pelas ideias contidas na coletânea Coleção das leis constitutivas das colônias inglesas confederadas sob o nome de Estados Unidos da América Setentrional, publicada em Paris, em francês, em 1778.

Em sua segunda inquirição à devassa, em 11 de julho de 1789, Luís Vieira faz referência presumível que havia lido e tinha conhecimento dos documentos constitucionais fundadores dos Estados Unidos da América. Sabe-se, pelos depoimentos contidos no processo judicial, que ele era um dos redatores dos preceitos da projetada república que se planejava instaurar em Minas Gerais. Em seu fala disse:

como anda escrita e impressa a história da América Inglesa, [...] tendo ele, Respondente, lido a sobredita história [...], podia muito bem suceder que -em alguma ocasião, sem reserva de pessoas, porque se não dirigia a fim algum particular- fizesse algum discurso ou conversasse sobre uma ou outra América, persuadido que nisso não cometia delito algum, por ser este fato muito próprio em sujeitos que têm alguma aplicação e versados na história (ADIM, 1978, vol. 2, p. 150).

Para desenvolver os planos legislativos dos inconfidentes, Luís Vieira apoiou-se na História das duas Índias, na Coleção das leis constitutivas das colônias inglesas da América do Norte e nos treze mapas que lhe foram sequestrados, para pensar os planos de defesa do território, em conjunto com as informações de salvaguarda lidos, muito provavelmente, na obra Elementos de arte militar de José Marques Cardoso. 
Sob o impacto das obras de ciências e dos escritos filosóficos da Ilustração identificados em sua livraria, assim como o modelo de independência das colônias inglesas no norte da América e dos saberes locais, o cônego Luís Vieira percebeu Minas Gerais e a revolta que ali se planejava dentro das contradições que separavam a colônia (o Brasil) e a metrópole (Portugal). Aliás, o seu modo de pensar, como a dos demais revoltosos eruditos, denota um entendimento ilustrado do mundo, o que se reforça pela "inventiva apropriação" do exemplo histórico da América inglesa, permeada pela leitura do abade Raynal e da Coleção das leis constitutivas das colônias inglesas, como ele mesmo declarou ter realizado em seu depoimento; possibilitando-nos enxergar indícios de leitura (Furtado y Starling, 2013, pp. 107-132; Villalta, 2015, p. 500).

\section{CONSIDERAÇÕES FINAIS}

O inventário da livraria do cônego Luís Vieira da Silva nos permite ter uma ideia dos tipos de obras científicas e filosóficas que circulavam nas Minas Gerais da segunda metade do século XVIII, assim como nos possibilita evidenciar prováveis indícios de leitura. Especificamente sobre seus textos científicos, observa-se a abundância de títulos relacionados à medicina, coincidindo com a tendência setecentista que defendia um caráter mais técnico e prático da ciência.

Nas suas estantes estavam os mais importantes e influentes pensadores do mundo ocidental, assim como textos inovadores da ciência moderna. Sua cultura livresca mostra-se em sintonia com as ideias da Ilustração que se divulgavam no continente europeu, apesar das dificuldades e do controle impostos pela censura para a chegada de livros na América portuguesa.

A provável "curiosidade" intelectual do cônego Luís Vieira o fez participar de debates de teor claramente conspiratório nos cenáculos literários existentes na cidade de Vila Rica. Ali é que entrou em contato com as obras de Raynal e com os textos constitucionais norte-americanos, reunidos no Recueil, possibilitando-lhe recorrer as ideias escritas nessas obras para interpretar o mundo em que vivia. Não é à toa que essa interpretação tendeu a identificar a difusão das ideias ilustradas como uma tomada de consciência da situação colonial e o exemplo da bem-sucedida revolução norte-americana traduzia a expectativa política pelo rompimento dos grilhões que prendiam Minas Gerais a Portugal. 
Os Estados Unidos, como objeto de sua boemia literária e fonte de inspiração, utilizando-se as felizes expressões propagadas por Robert Darnton e Luiz Carlos Villalta, em seus estudos sobre os sentidos das letras no mundo ocidental da época moderna, ilustra o seu posicionamento como agente histórico e homem de seu tempo.

A circulação de ideias e livros, em virtude de sua participação nas reuniões e pela "atual" biblioteca que possuía, o fez ser considerado um dos responsáveis pela elaboração das leis e dos planos militares que se pensavam para a futura república de Minas Gerais. Informações observáveis nos indícios de leitura que nos ficaram de suas "falas" no processo judicial aberto para julgar a Inconfidência Mineira de 1789 e nos livros científicos que possuía em sua livraria, identificados graças à versão manuscrita aqui utilizada, que nos propiciou conhecer os seus títulos com exatidão e número de volumes, mesmo aplicando sobre aquele inventário o recorte de separar apenas seus títulos científicos, mesmo se incorrendo na parcialidade de não observar aquela livraria como um todo.

\section{REFERENNCIAS}

Abreu, J. L. N. (2010). Higiene e conservação da saúde do pensamento médico luso-brasileiro do século XVIII. Asclepio, 62(1), 225-250.

Abreu, M. (2003). Os caminhos dos livros. Campinas: Mercado das Letras.

[ADIM] Autos de Devassa da Inconfidência Mineira (1976-1983). Brasília: Câmara dos Deputados/Belo Horizonte: Imprensa Oficial do Governo do Estado de Minas Gerais. 10 vols.

Algranti, L. M. (2004). Livros de devoção, atos de censura. Ensaios de história do livro e da leitura na América portuguesa, 1750-1821. São Paulo: Hucitec.

Anastasia, C. (2002). Inconfidência Mineira. São Paulo: Ática.

Arantes, J. T. (janeiro, 2018). A prática médica no Brasil colonial -entrevista com Ana Carolina de Carvalho Viotti. Agência Fapesp, 15. Recuperado de http://agencia. fapesp.br/a-pratica-medica-no-brasil-colonial/26987/

Araújo, J. de S. (1999). Perfil do leitor colonial. Ilhéus: Editus.

Burns, E. B. (1964). The enlightenment in two colonial Brazilian libraries. Journal of the History of Ideas, 25(3), 430-438.

Chartier, R. (1990). A história cultural. Entre práticas e representações. Lisboa: Difel/Rio de Janeiro: Bertrand Brasil. 
Darnton, R. (1990). O beijo de Lamourette. Mídia, cultura e revolução. São Paulo: Companhia das Letras.

Darnton, R. (1992). Edição e sedição. O universo da literatura clandestina no século XVIII. São Paulo: Companhia das Letras.

Darnton, R. (1996). O Iluminismo como negócio. História da publicação da Enciclopédia, 1775-1800. São Paulo: Companhia das Letras.

Darnton, R. (2014). Poesia e polícia. Redes de comunicação na Paris do século xviII. São Paulo: Companhia das Letras.

Diniz, S. G. (1959a). Bibliotecas setecentistas nas Minas Gerais. Revista do Instituto Histórico e Geográfico de Minas Gerais, 6, 333-344.

Diniz, S. G. (1959b). Um livreiro em Vila Rica no meado do século xVIII. Kriterion, 47-48, 180-195.

Doig, A. (1993). William Cullen and the eighteenth century medical world. Edinburgh: Edinburgh University Press.

Ducheyne, S. (2016). Petrus van Musschenbroek (1692-1761) on the scope of physica and its place within philosophia. Asclepio: Revista de Historia de la Medicina y de la Ciencia, 68(1). Dor: http://dx.doi.org/10.3989/asclepio.2016.02

Focas, J. (2002). Inconfidência Mineira. A história dos sentidos de uma história. Belo Horizonte: FALE-UFMG.

Former Fellows of The Royal Society of Edinburgh 1783-2002 (2006). Edinburgh: The Royal Society of Edinburgh. Recuperado de https://web.archive.org/ web/20061004113545/http://www.rse.org.uk/fellowship/fells_indexp1.pdf

Frieiro, E. (1981). O diabo na livraria do cônego. Belo Horizonte: Itatiaia/São Paulo: Edusp.

Furtado, J. P. (1998). Inconfidência Mineira. Um espetáculo no escuro (1788-1792). São Paulo: Moderna.

Furtado, J. F. (2009). Um cartógrafo rebelde? José Joaquim da Rocha e a cartografia de Minas Gerais. Anais do Museu Paulista, 17(2), 155-187.

Furtado, J. F. (2014). Seditious books and libertinism in the captaincy of Minas Gerais (18th century Brazil): the library of naturalist José Vieira Couto. Revista Complutense de Historia de América, 40, 113-136.

Furtado, J. F. y Monteiro, N. G. (2016). O Brasil na Histoire des Deus Index do abade Raynal. Varia Historia, 32(60), 731-777. DoI: http://dx.doi. org/10.1590/0104-87752016000300007

Furtado, J. F. y Starling, H. M. (2013). República e sedição na Inconfidência Mineira: leituras do Recueil por uma sociedade de pensamento. En K. Maxwell (ed.), O livro 
de Tiradentes. Transmissão atlântica de ideias políticas no século XVIII (pp. 107-132). São Paulo: Companhia das Letras.

Guimarães, L. C; Pitombeira, J. B. y Schubring, G. (2011). Manuel de Campos, um precursor. Llull: Revista de la Sociedad Española de Historia de las Ciencias y de las Técnicas, 34(74), 315-340.

Hettche, M. (2016). Christian Wolff. The Stanford Encyclopedia of Philosophy (winter edition). Recuperado de https://plato.stanford.edu/archives/win2016/entries/ wolff-christian/

Jardim, M. (1989). A Inconfidência Mineira: uma síntese factual. Rio de Janeiro: Biblioteca do Exército.

Jobim, L. C. (1987). O Santo Ofício da Inquisição no Brasil setecentista: estudo de uma denúncia. Estudos Ibero-Americanos, 2, 195-213.

Leite, P. G. (1995). Revolução e heresia na biblioteca de um advogado de Mariana. Acervo: Revista do Arquivo Nacional, 8(1-2), 153-166.

Leite, P. G. (2001). Leitores e leitura em Mariana nos séculos XVIII e XIX. Revista do Instituto Histórico e Geográfico de Minas Gerais, 24, 217-226.

Lessa, C. R. (1946). As bibliotecas brasileiras dos tempos coloniais: apontamentos para um estudo histórico. Revista do Instituto Histórico e Geográfico Brasileiro, 191, 339-345.

Lysagth, A. M. (2003). Banks, Sir. Joseph. En Dictionary of Canadian Biography. University of Toronto/Université Laval. Recuperado de http://www.biographi.ca/en/ bio/banks_joseph_5E.html

Mollier, J.-Y. (2006). Política, nação e sedição: o lugar dos impressos na construção da vida política-Brasil, Europa e Américas nos séculos XVIII-Xx. São Paulo: Annabluime.

Nava, P. (2003). Capítulos da história da medicina no Brasil. Cotia: Ateliê Editorial.

Neves, G. P. das (2000). Ilustração. En R. Vainfas (org.), Dicionário do Brasil Colonial (1500-1808) (pp. 296-299). Rio de Janeiro: Objetiva.

Raynal, A. (1993). A revolução da América. Rio de Janeiro: Arquivo Nacional.

Rodrigues, A. F. (2002). O clero e a conjuração mineira. São Paulo: Humanitas FFLCH-USP.

Rodrigues, A. F. (2010). A fortuna dos inconfidentes. Caminhos e descaminhos de bens de conjurados mineiros, 1760-1850. São Paulo: Globo.

Rodrigues, A. F. (2017). Sequestros de bens dos participantes da Inconfidência Mineira como fonte de pesquisa para a história do livro e das bibliotecas (1789), História (São Paulo), 36(35), 1-30. DoI: https://dx.doi.org/10.1590/1980-436920170000000035

Seqüestro dos bens do cônego Luiz Vieira da Silva (1901). Revista Trimestral do Instituto Histórico, 103, 159-160. 
Sevcenko, N. (1989). Aspectos irracionais do Iluminismo. Revista do Brasil, 4(10), 19-31. Singy, P. (2010). The popularization of medicine in the eighteenth century: writing, reading, and rewriting Samuel Auguste Tissot's Avis au peuple sur sa santé. The Journal of Modern History, 82(4), 769-800.

Souza, R. de F. e (2008). O Tiradentes leitor. Viçosa: Suprema.

Spinelli, M. (1990). A matemática como paradigma da construção filosófica de Descartes. Revista Cadernos de História e Filosofia da Ciência, 2(1), 5-15.

Todericiu, D. (1984). Balthasar-Georges Sage (1740-1824), chimiste et minéralogiste français, fondateur de la première Ecole des Mines (1783). Revue d'Histoire des Sciences, 37(1), 29-46. DoI: https://dx.doi.org/10.3406/rhs.1984.1973

Trindade, R. (1953). Arquidiocese de Mariana (2 tt.). Belo Horizonte: Imprensa Oficial. Villalta, L. C. (1997) O que se fala e o que se lê: língua, instrução e leitura. En L. de M. e Souza (org.), História da vida privada no Brasil, Cotidiano e vida privada na América portuguesa (pp. 331-385). São Paulo: Companhia das Letras.

Villalta, L. C. (2007a). Introdução-Educação e letras. En M. E. L. de Resende y L. C. Villalta (org.), História de Minas Gerais. As minas setecentistas (2 tt., vol. 2, pp. 249252). Belo Horizonte: Autêntica/Companhia do Tempo.

Villalta, L. C. (2007b). Ler, escrever, bibliotecas e estratificação social. En M. E. L. de Resende y L. C. Villalta (org.), História de Minas Gerais. As minas setecentistas (2 tt., vol. 2, pp. 289-311). Belo Horizonte: Autêntica/Companhia do Tempo.

Villalta, L. C. (2007c). As origens intelectuais e políticas da Inconfidência Mineira. En M. E. L. de Resende y L. C. Villalta (org.), História de Minas Gerais. As minas setecentistas (2 tt., vol. 2, pp. 579-607). Belo Horizonte: Autêntica/Companhia do Tempo.

Villalta, L. C. (2015). Usos do livro no mundo luso-brasileiro sob as Luzes. Reformas, censura e contestações. 2. ed. Belo Horizonte: Fino Trato.

Villalta, L. C. y Becho, A. P. (2007). Lugares, espaços e identidades coletivas na Inconfidência Mineira. En M. E. L. de Resende y L. C. Villalta (org.), História de Minas Gerais. As minas setecentistas (2 tt., vol. 2, pp. 555-578). Belo Horizonte: Autêntica/ Companhia do Tempo.

Wegner, R. (2004). Livros do Arco do Cego no Brasil colonial. História, Ciências, Saúde -Manguinhos, 11, 131-140.

Wisniak, J. (2013). Balthasar-Georges Sage. Revista CENIC -Ciencias Quimicas, 44(1). Recuperadodehttps://revista.cnic.edu.cu/revistaCQ/articulos/balthasar-georges-sage 